CATALAN REVIEW

Catalan Review

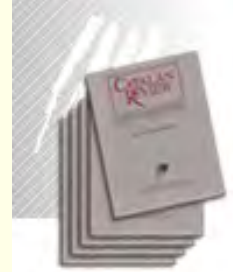

You are accessing the Digital Archive of the Catalan Review Journal.

By accessing and/or using this Digital Archive, you accept and agree to abide by the Terms and Conditions of Use available at http://www.nacs-

catalanstudies.org/catalan review.html

Catalan Review is the premier international scholarly journal devoted to all aspects of Catalan culture. By Catalan culture is understood all manifestations of intellectual and artistic life produced in the Catalan language or in the geographical areas where Catalan is spoken. Catalan Review has been in publication since 1986.
NORTH

AMERICAN

CATALAN

SOCIETY
Esteu accedint a l'Arxiu Digital del Catalan Review

A l' accedir i / o utilitzar aquest Arxiu Digital, vostè accepta i es compromet a complir els termes i condicions d'ús disponibles a http://www.nacs-

catalanstudies.org/catalan review.html

Catalan Review és la primera revista internacional dedicada a tots els aspectes de la cultura catalana. Per la cultura catalana s'entén totes les manifestacions de la vida intel lectual i artística produïda en llengua catalana o en les zones geogràfiques on es parla català. Catalan Review es publica des de 1986.

\title{
Idees entorn del llenguatge i de les llengües a l'ensenyament secundari públic de Barcelona: visibilitat, diversitat i correcció Pere Comellas
}

Catalan Review, Vol. XXI, (2007), p. 175- 205 


\section{IDEES ENTORN DEL LLENGUATGE I DE LES LLENGÜES A L'ENSENYAMENT SECUNDARI PÚBLIC DE BARCELONA: VISIBILITAT, DIVERSITAT I CORRECCIO*}

PERE COMELLAS

\section{ABSTRACT}

This article presents and discusses the results of a questionnaire completed by 74 secondary school teachers in Barcelona. The topics of the questionnaire revolved around linguistic representations, especially those relating to the visibility of linguistic diversity in secondary schools (e.g., the need to preserve languages, representations of language varieties, and so on). The responses from the teachers show considerable variation in their awareness of the presence of different languages in their surroundings; and make clear that identification with a state and the official status of a language are factors that contribute to creating visibility over and above the size of the community in the environment or the overall number of speakers. The data also reveal a certain degree of incoherence between general principles and concrete situations, and between situations close to the teachers (related to their own language) and alien situations. Finally, the results are related to variables that describe the language teachers, such as their age, first language, and the department to which they belong in the secondary school.

\section{INTRODUCCIÓ}

A1 llarg dels anys la sociolingüística catalana s'ha vist abocada a adaptar-se a situacions altament complexes i dinàmiques. Des dels anys seixanta del segle XX la teoria del conflicte lingüístic formulada per Aracil (Papers) oferia un model fonamentalment pensat per explicar la dinàmica d'una comunitat lingüísticament homogènia minoritzada pel fet d'estar inclosa en una estructura política al-loglota i assimilacionista: la comunitat catalanoparlant en l'àmbit de l'Estat espanyol. Segons aquesta teoria, quan una societat - per les raons que sigui, que en el cas català eren d'imposició política - utilitza per a certes funcions una varietat lingüística exògena, es crea una tensió que al capdavall només

${ }^{*}$ Aquest treball s'emmarca en el projecte La diversidad lingüustion en Cataluña: guia para materiales de acogida, del Programa Nacional de Humanidades (codi HUMzoo6-09478/FILO), finançat pel Ministerio de Educación y Ciencia i dirigit per la Dra. M. Carme Junyent. Agraeixo als avaluadors anònims de la Catalan Review els valuosos suggeriments i correccions que hi han fet. 
pot portar a dos finals: "o bé a l'eliminació del conflicte dins el sistema lingüistic donat, o bé a l'eliminació total del sistema per substitució" (Aracil, Papers 27). Aquesta és la síntesi que en fa Kremnitz (63):

Segons els sociolingüistes catalans, totes aquestes modificacions de l'ús lingưístic col-lecriu van cap a dues possibles direccions, és a dir, o cap a la substitució, vol dir, cap a la imposició total de la llengua dominant, o cap a la normalització, o sigui, cap al manteniment progressiu de la llengua dominada fins a la substitució total de la llengua que abans era la llengua dominant, cada una en un territori donat.

Aviat, però, i per causa del gran flux migratori que Catalunya va rebre provinent d'altres zones d'Espanya, "el conflicte lingüístic va deixar d'associar-se a la tensió interna del seu model cibernètic [d'Aracil] i va passar a aplicar-se a la relació entre dues llengües en competència en una mateixa societat, competència que acaba provocant el desplaçament total d'una d'elles" (Boix i Vila 97). La idea de conflicte es desplaçava d'una consideració intracomunitària a una d'intercomunitària, cosa que, més enllà de les implicacions teòriques, havia de provocar necessàriament un terrabastall en el projecte sociopolític que sempre hi havia hagut darrere de les inquietuds sociolingüístiques. Perquè en el primer model, l'aracilià original, es plantejava la necessitat que la comunitat catalanoparlant recuperés per a la seva llengua primera les funcions que el castellà havia anat ocupant de manera impositiva, en un procés que o s'aturava i es revertia o menava a la substitució, és a dir, a la desaparició del català. En canvi, la introducció del factor migració implicava la necessitat d'incorporar una comunitat al-loglọta, és a dir, suposava, sempre segons un model dicotòmic, l'assimilació lingüística dels castellanoparlants.

Aparentment, el terrabastall no es va produir. Plantejar clarament una planificació lingüística a la suïssa era molt difícil: el poder polític estatal no ho permetia i les dimensions de la comunitat de primera llengua castellana ho feien improbable per la via horitzontal. Així, els projectes de planificació institucionals es van anar movent en l'ambigüitat d'un horitzó de bilingüisme equilibrat i ideal que si no volia dir "cada territori la seva llengua" (i això, ja ho hem dit, no ho permet l'estat), en teoria era impossible (o normalització o substitució). Però si ho volia dir, llavors podia ser fàcilment deslegitimat: per què cal evitar la substitució lingüística quan es tracta del català i fomentar-la quan es tracta del castellà? L'única resposta convincent és: en un determinat territori, només hi ha una llengua legítima.

La percepció del bilingüisme com a amenaça - tant per l'evidència que la bilingüització és una condició sine qua non per a la substitució cóm pel fet que es tracti fonamentalment d'una expressió atribuïda a projectes homogeneitzadors - i la convicció que un conflicte lingüís- 
tic només té dues sortides possibles ha marcat profundament la visió de la situació catalana. Globalment, la planificació lingüística oficial no deixa de tenir la mateixa filosofia jacobina clàssica que ha inspirat les polítiques lingüístiques de gairebé tots els estats d'Europa, per bé que, afortunadament, amb uns límits ètics que aquesta sovint no ha tingut i que marquen una diferència fonamental (i qualitativa) en les pràctiques (e.g., Woolard 108-09; Boix i Vila 326). Alhora, però, ja fa anys que es poden trobar discursos que trenquen la lògica dicotòmica, que diria Albert Bastardas. L'any 1992, per exemple, M. Carme Junyent encarava la qứestió des d'una perspectiva global, que revisava profundament els pressupòsits de la idea de conflicte: "El futur del català no es pot deslligar del futur de totes les llengües i molt especialment de totes les amenaçades. La preservació del patrimoni lingüistic ha de ser global perquè sigui plausible" (Junyent, Vida 1o). El multilingüisme no es pot entendre com una anomalia transitòria, un factor distorsionador, sinó com un element intrínsec a la dinàmica lingüística humana, i no només avui i en societats industrialitzades, sinó arreu al llarg de la història. De fet, allò que caldria oposar al bilingüisme substituïdor no és pas la monolingüització forçada, sinó el manteniment del multilingüisme.

Aquest entramat d'idees s'emmarca, doncs, en la reivindicació global de la diversitat, per cert una de les línies de força d'una part important de la sociolingüística arreu del món, així com d'altres ciències socials, fins al punt que gairebé s'ha tornat un lloc comú i una posició que aparentment desperta poca oposició explícita. Tanmateix, com deia Borges, és fàcil professar una filosofia, però és molt difícil pensar d'acord amb ella. La bona premsa que té la diversitat ha provocat de debò un canvi en les ideologies lingüístiques? Hem deixat enrere l'entramat de representacions associat al monolingüisme assimilacionista? Hem interioritzat de debò que la diversitat no és una amenaça? Ho estem provant de fer, si més no, justament quan Catalunya s'ha convertit en un destí d'emigració multilingüe de primer ordre? Són preguntes encara més pertinents precisament per això, i el nostre espai és especialment idoni per fer-se-les, perquè fa molt de temps que hi preocupen les llengües, el paper social que tenen, el que signifiquen. D'un temps ençà, l'estudi de diferents aspectes de la diversitat ha ocupat, en efecte, nombrosos especialistes també de l'àrea catalanòfona. Una part gens negligible d'aquest esforç s'ha centrat en diverses qüestions relacionades amb l'ensenyament (com ara Junyent, Diversitat, Nussbaum i Bernáus; Unamuno; Noguerol i González; Dooly, "How Aware"; Dooly, Linguistic). Aquest és també el camp en què hem centrat el present treball, hereu de Comellas ("Representacions").

També la contribució de Dooly en aquest mateix volum estudia aspectes relacionats amb la diversitat lingüística a l'escola. Tanmateix, $i$ a fi d'oferir una perspectiva complementària a la d'aquesta autora, en 
aquest article ens limitarem als aspectes quantitatius de la recerca de 2005 , particularment dissenyats amb l'objectiu de posar en evidència certes tendències ideològiques, certes "creences" (per fer servir l'expressió de Dooly) del professorat d'ensenyament secundari obligatori (ESO) entorn d'alguns tòpics lingüístics. Creiem que tant les diferències metodològiques substancials com el fet que ens apropem a tipologies de professorat i a criteris de diversitat parcialment divergents garanteixen enfocaments prou diferenciats alhora, però, que compartim determinats pressupòsits sobre la construcció de significats i la categorització de col-lectius, temes per als quals em remeto al seu treball.

\section{REPRESENTACIONS}

En paraules de Potter (I2), "els mons en què vivim no són senzillament allà a fora, com fenòmens objectius, sinó que són construccions fruit de tot un ventall d'acords i de pràctiques socials". Com Bourdieu posa en evidència, la participació en aquestes construccions de significat no és gens ni mica igualitària. Potser la formulació més clara i breu que es pot fer d'aquest punt de vista és el resum que en fa Aracil (Dir 57): "En tota relació de poder, el qui mana sempre té raó - i no mana pas perquè tingui raó". Doncs bé, l'escola és sens dubte un actor central tant en la creació com en la reproducció de representacions: "les ideologies s'adquireixen bàsicament a través del discurs, i no només com un tipus específic de 'comportament' o acció. Més que qualsevol altra institució, l'escola i els mitjans de comunicació porten a terme aquest rol" (Van Dijk 46). Segons Heller (I8I), "la veritable qüestió és saber quines són les fonts de la desigualtat social i quin paper fan les pràctiques lingüístiques en la reproducció d'aquestes". Emili Boix aposta també per una línia semblant en intentar definir els objectius que, al seu parer, hauria de tenir l'antropologia lingüística: "a) mostrar els mecanismes concrets mitjançant els quals les representacions lingüístiques dominants discriminen, $\mathrm{i}$ b) ajudar a construir representacions radicalment defensores de la diversitat lingüística" (Boix, "Les representacions" 10).

Entenem les representacions lingüístiques com un subconjunt de les representacions socials, i per a aquestes adoptem la definició de Jodelet (53): "forma de coneixement, socialment elaborat i compartit, que té una visió pràctica i que participa en la construcció d'una realitat comuna a un grup social". Les representacions socials, com a constructes elaborats a través de la interacció, són necessàriament dinàmiques i $s$ 'actualitzen constantment (es reforcen, es modifiquen i es qüestionen) a través del discurs. Així, qualsevol aproximació discursiva a aquestes - com el present treball- implica una certa manipulació i una reelaboració. En aquest camp també l'observació i l'observador contaminen la 
cosa observada i la frontera subjecte-objecte no té límits precisos. Tanmateix, creiem que això no invalida ni els resultats ni el sentit de la recerca, que al capdavall també pretén una contribució discursiva a la construcció de representacions.

A partir d'aquestes premisses, ens interessava veure quina mena de creences sosté i transmet el professorat d'ESO entorn de la visibilitat de la diversitat lingüística, l'estratificació de les varietats lingüístiques $i$ la consideració sobre la variació, per tal de valorar si la tendència és reproduir representacions diversofobes, com tradicionalment ha fet l'escola, ${ }^{\circ} \mathrm{o}$ valorar la diversitat. Pel que fa a la visibilitat, considerem que es tracta d'un indicador important de reconeixement, la condició indispensable per atorgar estatus d'existència. La visibilitat és un dels factors que contribueixen al prestigi. Calvet (171) explica el fet mitjançant el concepte d' "externalitats de xarxa", manllevat a l'economia: com més creiem que una cosa és útil, més la tenim en compte, cosa que en fa augmentar la representació d'utilitat. Quant a l'estratificació, situar la variació lingứística en una escala permet establir criteris jeràrquics que sovint són projeccions d'una realitat social a una realitat lingüística i que fonamenten representacions discriminatòries suposadament basades en trets lingüístics (Lippi-Green).

\section{BASES DE L'ESTUDI}

Les dades en què es basa aquest treball provenen d'una enquesta contestada per 74 professors de secundària de vuit instituts públics de Barcelona (Annex). Com es pot veure, la major part de l'enquesta consisteix a qualificar afirmacions segons una escala de sis possibilitats que va de desacord extrem a acord extrem. Pel que fa als vuit instituts, es va intentar que corresponguessin a zones de Barcelona socialment $i$ geogràficament força diferenciades, per bé que intencionadament es va procurar sobrerepresentar centres especialment rics en diversitat d'orígens de l'alumnat, per tal com se suposava que aquesta circumstància implicaria un nivell més alt de reflexió entorn de les qüestions lingüístiques. Els instituts on es van passar les enquestes són:

IES Rambla Prim: situat al barri del Besòs, districte de Sant Martí de Provençals, zona considerada de renda baixa (la mitjana del districte l'any 200 s era de 85,7 sobre una mitjana too a tot el municipi, segons les estadístiques municipals). L’any 2006, segons el padró municipal, vivien al districte un $12,58 \%$ d'estrangers. El percentatge d'alumnat no universitari estranger també en el conjunt del districte el 2005 era de ro,82. Tanmateix, hi ha una gran concentració d'estrangers en l'ensenyament públic, i particularment en aquest institut situat en una zona de recepció d'immigració superior a altres sectors del mateix districte. 
IES Narcís Monturiol: a la zona de Montbau, barri de la Vall d'Hèbron, districte d'Horta Guinardó. Es tracta d'un districte socialment molt divers, amb sectors residencials d'alta renda i sectors de concentració de població de rendes modestes, com és el cas de la zona on s'ubica aquest institut, poblada sobretot per immigrants vinguts d'altres territoris espanyols fa unes dècades.

IES Sant Josep de Calasanç: situat a la zona fronterera entre els barris del Guinardó i de l'Eixample. És un sector de renda mitjana, amb població immigrant inferior a la mitjana.

IES Milà i Fontanals: situat al barri del Raval, districte de Ciutat Vella, al centre històric de Barcelona. El districte té una renda mitjana de les més baixes de la ciutat ( 72 sobre una mitjana de roo l'any 2005), l'atur més alt $(\mathrm{I} 4 \%)$ i l'índex de residents estrangers també més alt, amb molta diferència ( $42,2 \%$ davant d'una mitjana a la ciutat de $15,3 \%$ l'any 2006).

IES Miquel Tarradell: situat també al barri del Raval, molt a prop de l'anterior i per tant amb les mateixes característiques socials. De fet, tots dos instituts tenen des de fa anys una altíssima concentració d'alumnat estranger, superior al $80 \%$. A més, aquest institut ha demostrat sovint una especial sensibilitat per a la valorització i la difusió de la seva diversitat cultural $\mathrm{i}$ lingüística.

IES Galileo Galilei: situat al barri de Roquetes-Verdum, al districte de Nou Barris, una zona de creixement poblacional motivat per la immigració espanyola de la segona meitat del segle Xx i actualment també receptora d'immigració estrangera. La renda mitjana del districte és la més baixa de la ciutat, una mica per sota de Ciutat Vella. L'índex d'alumnat estranger era del $15,34 \%$ de mitjana l'any 2005 , per bé que en els instituts públics la concentració és molt superior.

IES Joan Corominas: situat al barri de la Bordeta-Hostafrancs, districte de Sants-Montjuïc. Es tracta d'un centre especialment receptor d'alumnat estranger, d'una banda per la concentració poblacional, perô també per la política del centre. Atén també una important població gitana secularment arrelada al barri. L'any 2005 la direcció afirmava estar també per sobre del $70 \%$ d'alumnat estranger matriculat. $\mathrm{La}$ renda mitjana del districte aquest mateix any era de 80,7 .

IES Les Corts: al centre del barri de les Corts. El districte disposava d'una renda mitjana de 139,4 l'any 2005 (el segon districte més ric de la ciutat $i$ un dels tres que se situa per sobre de la mitjana general). La taxa d'alumnat estranger és també una de les més baixes de la ciutat $(4,29 \%$ l'any 2005) i el mateix institut, tot i ser públic, reconeixia la poca presència d'immigració recent al centre. D'altra banda, el perfil social d'una part de la immigració era del tot diferent (havien tingut, per exemple, fills de diplomàtics magrebins o joves aspirants a jugadors del Barça, residents al centre de formació que el club té al barri).

L'eríquesta es va fer arribar a la totalitat del professorat dels insti- 
tuts triats, però un percentatge força baix, prop del $18 \%$, la va retornar completada. Exactament la meitat de les enquestes contestades, és a dir 37 , són de professorat de llengües. L'àrea de socials està representada per to enquestes, matemàtiques i ciències per 6 cadascuna, música 5 , tecnologia 4, psicopedagogia $2 \mathrm{i}$ la resta són respostes úniques. Quant a la llengua primera dels enquestats (que juntament amb l'especialitat són les variables més considerades en el treball), 43 es declaraven catalanoparlants, 30 castellanoparlants, i un va declarar que ho eren totes dues.

\section{LLENGÜES VISIBLES I LLENGÜES INVISIBLES}

L'existència de parlants de múltiples llengües en els instituts barcelonins no implica necessàriament la visibilitat del fenomen. Sovint el mateix alumnat oculta o dissimula trets culturals diferenciadors de manera conscient. Simètricament, tant l'alumnat local com el professorat manifesten poc interès pel coneixement concret d'aquests trets. L'enquesta passada al professorat sol-licitava una llista de les llengües de les quals hi hagués parlants a l'institut. Es tractava de posar en evidència què es fa visible de la nova diversitat (per cert, molt més àmplia del que sovint percebem en general, com ho mostra l'estudi dut a terme pel Grup d'Estudi de Llengües Amenaçades (GELA) l'any 2005, que va suposar la base d'una exposició: Junyent et al,, Les llengües).

En el gràfic I representem els resultats globals de la pregunta, ponderats com si cada institut hagués tingut el mateix nombre d'enquestes. El valor màxim possible $(\mathrm{I})$ representaria que totes les enquestes han esmentat aquella llengua:

GRAFIC I

REPRESENTACIÓ PONDERADA DE LES LLENGÜES MÉS VISIBLES (EL VALOR 1 REPRESENTARIA QUE TOTS ELS ENQUESTATS HAN ESMENTAT AQUELLA LLENGUA)

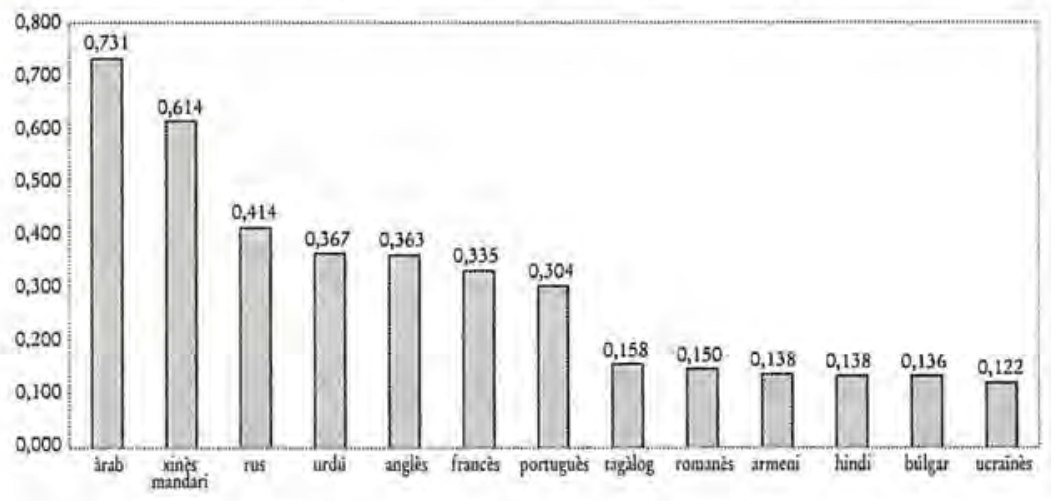


El primer que cal ressaltar del gràfic r és la forta presència de llengües "estatals". Pel que fa al primer classificat, l'àrab, la immensa majoria de l'alumnat que es podria considerar d'aquest origen és marroquí, i només una enquesta especifica aquesta varietat d'una manera diferenciada (és molt poc comú considerar les diferents varietats de l'àrab com a llengües). Una altra qüestió és la de l'amazic, que només assenyalen deu professors (i que en percentatge ja queda fora del gràfic). Pel que $\mathrm{fa}$ al xinès, únicament dos professors es mostren conscients de la varietat lingüística dels alumnes xinesos (un anomena la varietat de Xangai i l'altre el cantonès). Però la immensa majoria percep només el xinès oficial. Un cas semblant, per bé que menys extrem, és el de l'urdú i la resta de llengües del Pakistan. Bona part dels pakistanesos de Barcelona parlen panjabi com a $\mathrm{LI}_{\mathrm{I}}$ però en canvi l'urdú és visible per a 34 professors i el panjabi només per a 7, mentre que només 2 detecten el paixto. Entre les llengües de Filipines també apareix destacat el tagàlog, amb 13 professors, mentre que les altres llengües de la zona esmentades són molt menys visibles (3 d'ilocano i 2 de pangasinan, ambdues a I'IES Miquel Tarradell, situat en una zona de forta presència de la comunitat d'origen filipí).

Del llistat total de llengües esmentades ( 46 referències), aproximadament el $54 \%(25)$ tenen un nom que fa referència directa a un topònim estatal o subestatal (catală, gallec). Les 12 primeres llengües percebudes (fins a l'amazic) són totes oficials. I de les 46 anomenades, només 16 no són llengües estatals. D'aquestes setze, algunes de fet tenen també algun estatus d'oficialitat (com el quítxua i l'aimara a Perú i Bolívia, per bé que no en peu d'igualtat amb l'espanyol, o el panjabi $i$ el paixto). ${ }^{2}$ També per territoris hi ha un gran desequilibri: 18 d'europees, 17 d'asiàtiques, 6 d'africanes ( 3 del Magrib comptant l'àrab com a tal i com a àrab marroquí, $\mathrm{i}$ únicament 3 de subsaharianes), 3 d'americanes $i_{2}$ que no es van poder identificar.

D'altra banda, l'escassa visibilitat de llengües no oficials està molt mal repartida per instituts. La major part de les 52 mencions a llengües no oficials es concentren a l'IES Miquel Tarradell i a l'IES Rambla Prim (i aquest juga amb avantatge en magnituds absolutes, perquè té el nombre d'enquestes més alt). A més, cal recordar que vuit de les llengües no oficials citades només tenen un valor. Un sol professor d'aula d'acollida, molt millor informat que la resta pel que fa a les llengües primeres de l'alumnat, pot ser el responsable de la presència de diverses d'aquestes llengües en el resultat global. ${ }^{2}$ Al gràfic 2 es representen,

'S'han inclòs el paixto i el panjabi en les llengües no oficials perquè, tot i que la primera és oficial a l'Atganistan i la segona al Panjab indi, la percepció als instituts de Baŕcelona prové de l'alumnat pakistanès, estat en el qual no són oficials.

${ }^{2}$ Les aules d'acollida concentren temporalment Palumnat acabat d'arribar per tal de 
amb un diagrama de caixes, les diferències en la quantitat de llengües citades en les enquestes per instituts. Els extrems superior i inferior de cada diagrama indiquen els valors extrems, tret dels casos en què hi ha un valor especialment atípic (representat per un punt) com a l'IES Joan Corominas, al Milà i Fontanals i al Narcís Monturiol. Els límits de cada caixa representen la mediana del quartil superior i del quartil inferior respectivament, $\mathrm{i}$ la línia gruixuda representa la mediana del centre.

GRAFIC 2

DiAGRAMA DE CAIXES DEL NOMBRE DE LLENGUUES ESMENTADES PELS ENQUESTATS PER INSTTTUTS

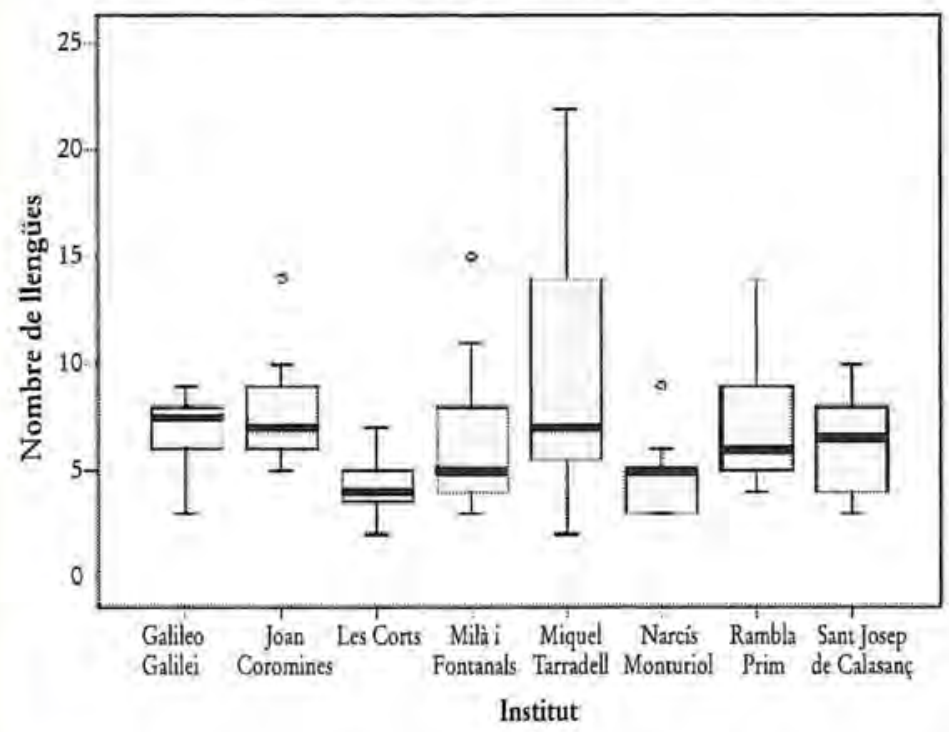

La resposta mínima és 2, lògicament (per bé que, en instituts com el de la Rambla Prim en alguna entrevista s'arribava a afirmar que el català era pràcticament absent entre l'alumnat). Però aquest mínim només apareix a dos centres, el de Les Corts i el Miquel Tarradell. Cal

dotar-lo de competència lingüística suficient en català per poder seguir les classes normals. Vam poder comprovar que a vegades les aules d'acollida són - tant com espais d'adquisició del català - àmbits d'intercanvi cultural i de reconeixement i descobriment mutus entre alumnat de diferent origen i professorat. Per a una aproximació a la problemàtica de l'acollida escolar a Catalunya, vegeu Alegre. 
dir que sorprèn que hi hagi una resposta (encara que és una de sola) tan minsa en aquest segon centre, un dels més multilingües sens dubte de Catalunya, multilingüisme que evidencia un diagrama notòriament més extens que el de la resta (la dispersió en el nombre de llengües citat és de molt la més alta). De fet, destaquen en el diagrama quant a percepció homogènia a la baixa -és a dir, on en general el professorat percep la presència de poques llengües - l'IES Les Corts i l'IES Narcís Monturiol. ${ }^{3}$ En efecte, les entrevistes confirmen que l'alumnat de llengües diferents del català i el castellà és escàs en aquests dos instituts. En canvi, és sorprenent la caixa que correspon al Milà i Fontanals, on la percepció immediata de qualsevol visitant és la d'un ampli multilingüisme, del tot comparable amb el del Miquel Tarradell, i tanmateix la percepció de les enquestes és molt més baixa. De fet, les enquestes del Milà mostren una visibilitat de llengües per sota del Joan Coromines (amb una alta concentració d'alumnat estranger), però també del Galileo Galilei, de Nou Barris, i del Rambla Prim, i gairebé idèntica a la del Sant Josep de Calasanç (i encara la mediana d'aquest és més alta). Tots aquests instituts, però, estan ubicats en zones de Barcelona amb uns índex d'immigració notablement inferiors al del Raval.

Cal remarcar que l'IES Miquel Tarradell, a banda de la ubicació al cor del Raval i de l'ampla majoria d'alumnat nascut fora de Catalunya ( $80 \%$ segons el web de l'institut) $i$ amb una gran varietat, ha tingut des de fa temps una política de visibilització i valoració del multilingüisme molt destacada, la qual cosa sembla que té un efecte en les representacions del professorat.

\section{LLENGÜES QUE VAL LA PENA D'APRENDRE}

Creu el professorat que aprendre llengües és positiu? Així, genèricament formulat, sens dubte que si. Tanmateix, es tractava de veure si es podia confirmar l'existència d'una jerarquització de llengües a l'escola. Una de les quiestions de l'enquesta, dones, era: "Anoteu per ordre d'importància les sis llengües que considereu que seria ideal que els vostres alumnes dominessin". Naturalment, els factors que porten cadascú a establir un determinat ordre d'importància són molt complexos. L'observació que es pretenia fer aquí era sobretot en dos sentits: a) si hi havia consens social ampli entre el professorat quant a l'ordre d'im-

${ }^{3}$ En aquest darrer cas, amb una observació atípica, la de l'enquesta número 22, que llista nou llengües. Tanmateix, l'enquestat curiosament palesa conèixer el país d'origen d'alumnat estranger, però no està segur del nom de la llengua que parlen. Així, les tres últimes llengües que anota són: llengua d'Uzbekistan, llengua d'Armènia i llengua d'Iran (i col-loća un interrogant a continuació de cadascuna). 
portància de les llengües per a l'alumnat o bé es detectaven variacions sensibles, i b) si es prenia en consideració de manera rellevant la importància d'adquirir un domini acadèmic de la llengua familiar.

Per tal d'ordenar els resultats i poder-los situar en una escala quantitativa, es van atorgar sis punts a la llengua escollida com a primera opció, cinc a la segona, quatre a la tercera, etc. No s'oferia explícitament la possibilitat de col-locar dues llengües en la mateixa posició, però algun enquestat ho va fer, cas en què les dues respostes obtenen la mateixa puntuació, la que els pertoca segons la posició triada. La llista de llengües que obtenen una puntuació mínima (per sobre de o,I) són les representades a la taula $\mathrm{I}$.

Per tal de compensar el nombre d'enquestes diferent per instituts, oferim els resultats ponderats. El valor to és el màxim possible $\mathrm{i}$ indicaria que totes les enquestes han escollit aquella llengua com a opció primera.

\section{TAULLA I}

LLENGÜES QUE L'ALUMNAT IDEALMENT HAURIA DE DOMINAR SEGONS ELS PROFESSORS (EL VALOR IO REPRESENTARIA PRIMERA OPCIÓ DE TOT EL PROFESSORAT ENQUESTAT)

\section{Institut d'Educació Secundària}

Rambla Narcís S. Josep de Milà i Miquel Galileo Joan Les Corts

Prim Monturiol Calasanç Fontanals Tarradell Galilei Coromines

Total

Llengües

\begin{tabular}{llllllllll}
\hline Català & 9,8 & 9,81 & 9,79 & 9,44 & 8,48 & 9,17 & 9,52 & 9,76 & 8,42 \\
Castellà & 8,43 & 8,33 & 8,54 & 8,7 & 7,42 & 9,17 & 8,33 & 8,57 & 7,50 \\
Anglès & 5,98 & 6,67 & 7,29 & 6,3 & 6,67 & 6,39 & 6,43 & 6,67 & 5,82 \\
Francè̀s & 2,55 & 4,26 & 3,75 & 2,59 & & 4,72 & 4,29 & 4,05 & 2,91 \\
Alemany & 1,18 & 2,78 & 1,67 & 0,74 & 0,45 & 3,33 & 1,67 & 2,38 & 1,58 \\
Àrab & 1,86 & & 1,04 & 2,04 & 0,76 & 0,83 & 0,48 & 1,19 & 0,91 \\
Pròpia & 0,2 & 0,74 & & & 4,55 & & 1,43 & & 0,77 \\
Xinès & 0,69 & & 0,63 & 0,56 & 0,15 & 1,11 & 0,48 & 0,95 & 0,51 \\
Italià̀ & 0,39 & 0,37 & 0,42 & & & 0,28 & 0,71 & 1,67 & 0,43 \\
Rus & 0,39 & 0,19 & 0,42 & 0,37 & & & & & 0,15 \\
Portuguès & 0,1 & 0,19 & & & & & 0,95 & & 0,14 \\
\hline
\end{tabular}


La taula revela de seguida que hi ha una pauta clara de preferències. Català i castellà, llengües oficials i primeres de la gran majoria de la població, encapçalen la llista. L'anglès es considera la llengua estrangera més important d'aprendre en general. Fins i tot en algunes enquestes l'opció "anglès" apareix com a segona opció d'aprenentatge prioritari. En quatre dels vuit instituts, la mitjana iguala o supera el 6,67, xifra que representaria tercera opció per a la totalitat del professorat. A continuació, per bé que ja força lluny, vénen el francès i l'alemany. L'àrab és la primera opció no europea, per davant del xinès. Cap altra llengua no europea obté mitjana general per sobre del o,1.

A banda de confirmar l'hegemonia representacional de l'anglès - el consens entorn de l'anglès és ampli i molt recolzat per l'escola i els mitjans de comunicació-, la taula ofereix dos aspectes que cal subratllar. En primer lloc, que el professorat percep que les llengües estrangeres importants per als seus alumnes no són necessàriament les que tenen més a prop, les del seu voltant. Si comparem les llengưes més necessàries d'aprendre amb les més visibles, observem un decalatge considerable. Anglès, francès i alemany són menys visibles a l'institut que àrab, urdú o rus, i tanmateix tenen més prioritat d'aprenentatge. Pel que fa al francès, que conserva un paper molt important en les representacions de prioritat d'aprenentatge del professorat, probablement hi ha diversos factors que contribueixen a posar-lo a la llista: tradició escolar, passat com a llengua internacional, prestigi cultural o proximitat geogràfica. Encara que moltes vegades s'argumenta que el nombre de parlants d'una llengua és proporcional a la seva utilitat o importància, evidentment un cop més les enquestes desmenteixen no ja que això sigui un fet ono, sinó que realment ho considerem així. Llengües com el bengalí o el hindi, amb moltíssims més milions de parlants que el francès, l'alemany o l'italià, no apareixen a la llista.

La segona observació és la posició de la "llengua pròpia". D'una banda es podria pensar que moltes enquestes no l'esmenten per la senzilla raó que es dóna per suposada, que la pròpia llengua no cal aprendre-la. Però això seria contradictori amb el fet que totes les enquestes sí que esmenten el català i el castellà, malgrat ser conscients (en uns instituts més que en altres) que bona part de l'alumnat en té una de les dues o totes dues com a primera llengua ( $\mathrm{LI}_{\mathrm{I}}$.

Per tant, es pot deduir que el professorat entén la qüestió en termes academicistes, de lectoescriptura i domini de l'estàndard. És molt baixa, doncs, la préocupació que manifesten les enquestes per la potenciació d'una alfabetització que inclogui la Li diferent de les oficials a Catalunya. I és també desigual: a quatre dels instituts no hi ha ni una sola rêsposta de "Ilengua pròpia": Sant Josep de Calasanç, Galileo Galilei, Les Corts i Milà i Fontanals. Dels altres quatre destaca moltíssim el Miquel Tarradell, on 6 de les II enquestes col-loquen aquesta 
opció en alguna posició. La resta, Joan Coromines, Narcís Monturiol i Rambla Prim, tenen només una enquesta on hi figuri en alguna posició d'importància la llengua pròpia. Per tant, sense l'IES Miquel Tarradell l'opció "llengua pròpia" no tindria cap pes. Novament sembla que el treball en les percepcions i en els coneixements del professorat entorn de les llengües i les cultures dels alumnes implica un canvi de representacions.

\section{LA CONSERVACIÓ DE LES LLENGÜES DE LES PERSONES MIGRANTS}

Tanmateix, la conservació de la llengua pròpia en persones desplaçades fora de l'àmbit lingüístic tradícional té força suport en les enquestes quan es tracta del català. L'enquesta proposava la següent afirmació: "És molt positiu que les comunitats catalanes instal-lades a altres zones d'Espanya mantinguin la llengua catalana a casa $i$ la transmetin als fills". Totes les respostes manifesten un grau d'acord positiu, per bé que en diferent mesura.

\section{TAULA 2}

GRAU D'ACORD AMB L'AFIRMACIÓ "ÉS MOLT POSITIU QUE LES COMUNITATS CATALANES INSTAI-LADES A ALTRES ZONES D'ESPANYA MANTINGUIN LA LLENGUA CATALANA A CASA 1 LA TRANSMETIN ALS FILLS"

\begin{tabular}{lrr}
\hline Grau d'acord & Freqüència & Percentarge \\
\hline 3: d'acord amb molts matisos & 5 & 6,8 \\
4: d'acord en línies generals & 9 & 12,2 \\
5: totalment d'acord & 59 & 79,7 \\
Total valids & 73 & 98,6 \\
No contesten & 1 & 1,4 \\
Total & 74 & 100,0 \\
\hline
\end{tabular}

Com es pot veure en la taula 2 , un $79,7 \%$ dels enquestats estan totalment d'acord amb el fet que els emigrants catalanoparlants conservin la llengua.

Només cinc de les 73 respostes mostren un grau d'acord reticent, tebi, de les quals quatre no tenen el català com a llengua primera, com es constata en la taula que explicita aquest criteri de LI. 
TAULA 3

GRAU D'ACORD SOBRE LA CONSERVACIÓ DEL CATALÀ FORA DE L'ÀMBIT LINGÜISTIC SEGONS LA LLENGUA PRIMERA DELS ENQUESTATS

\begin{tabular}{|c|c|c|c|c|c|c|c|c|}
\hline \multicolumn{9}{|c|}{$\begin{array}{l}\text { És molt positiu que les comunitats catalanes instal lades a altres zones } \\
\text { d'Espanya mantinguin la llengua catalana a casa i la transmetin als fills. }\end{array}$} \\
\hline & & \multicolumn{4}{|c|}{ Grau d'acord } & \multicolumn{2}{|c|}{ 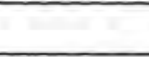 } & \multirow[b]{2}{*}{ Total } \\
\hline & & 0 & 1 & 2 & 3 & 4 & 5 & \\
\hline \multirow[t]{2}{*}{$\mathrm{LI}$} & català & 0 & 0 & 0 & I & 6 & 35 & 42 \\
\hline & castellà & 0 & 0 & 0 & 4 & 3 & 24 & 31 \\
\hline Total & & 0 & 0 & o & 5 & 9 & 59 & 73 \\
\hline
\end{tabular}

Sobre aquesta qưestió, però, hi havia a l'enquesta una afirmació oposada: "És bo per als fills d'emigrants que els pares els parlin en la llengua d'aquíi no en la seva". En aquest cas sí que es van obtenir respostes en tot l'espectre possible.

\section{TAULA 4}

GRAU D'ACORD AMB L'AFIRMACIO “'ÉS BO PER ALS FILLS D'EMIGRANTS QUE ELS PARES ELS PARLIN EN LA LLENGUA D'AQUf I NO EN LA SEVA"

\begin{tabular}{lrr}
\hline \multicolumn{1}{c}{ Grau d'acord } & Frequiència & Percentatge \\
\hline o: total desacord & 24 & 32,4 \\
I: força en desacord & I6 & 21,6 \\
2: no gaire d'acord & I2 & 16,2 \\
3: d'acord amb molts matisos & I2 & 16,2 \\
4: d'acord en línies generals & 4 & 5,4 \\
5: totalment d'acord & 5 & 6,8 \\
Total vàlids & 73 & 98,6 \\
No contesten & I & 1,4 \\
Total & 74 & 100,0 \\
\hline
\end{tabular}

Se suposa que una resposta coherent davant de les dues afirmacions havia de ser simètrica, és a dir, a un grau d'acord alt amb la idea que un"emigrant català ha de conservar la llengua li havia de correspondre un grau d'acord baix amb la idea que un immigrant a Cata- 
lunya ha de renunciar a transmetre la seva llengua primera, i al contrari. Però la taula 4 mostra prou bé un cert grau d'incoherència. Només prop del $32 \%$ del professorat enquestat es mostra del tot en desacord amb la substitució lingüística dels immigrants a Catalunya, mentre que totalment contraris a la substitució dels emigrants catalanòfons ho eren un $80 \%$. D'altra banda, 21 enquestes opinen (amb diferent intensitat) que sí que és positiu que els pares immigrants deixin de transmetre la seva llengua, però ningú no trobava oportú que ho fessin els catalans a Espanya.

Híté la llengua primera del professorat alguna cosa a veure, en aquesta qüestió? Vegem-ho en la taula corresponent.

\section{TAULA 5}

TRANSMISSIÓ DE LA PRÓPIA LLENGUA EN SITUACIÓ D'EMIGRACIÓ SEGONS LA LLENGUA PRIMERA DELS ENQUESTATS

\section{És bo per als fills d'emigrants que els pares els parlin en la llengua d'aquí i no en la seva.}

Grau d'acord

\begin{tabular}{|c|c|c|c|c|c|c|c|}
\hline & 0 & I & 2 & 3 & 4 & 5 & Total \\
\hline $\begin{array}{l}\text { Li català } \\
\text { castellà }\end{array}$ & $\begin{array}{c}9(21,43 \%) \\
15(48,39 \%)\end{array}$ & $\begin{array}{c}10(23,81 \%) \\
6(19,35 \%)\end{array}$ & $\begin{array}{l}8(19,05 \%) \\
4(12,9 \%)\end{array}$ & $\begin{array}{l}8(19,05 \%) \\
4(12,9 \%)\end{array}$ & $\begin{array}{l}3(7,14 \%) \\
I(3,23 \%)\end{array}$ & $\begin{array}{l}4(9,52 \%) \\
1(3,23 \%)\end{array}$ & $\left\{\begin{array}{l}42 \\
31\end{array}\right.$ \\
\hline Total & 24 & 16 & 12 & 12 & 4 & 5 & 73 \\
\hline
\end{tabular}

Hi ha un major grau d'incoherència entre el professorat de llengua primera catalana. Així doncs, una part del professorat de Li català (més d'un $35 \%$ ) considera el benefici immediat per a la pròpia llengua un valor superior al principi general de conservació lingüística a través de la transmissió. En canvi, només 6 professors de Li castellà (un I9\%) veuen adequada la ruptura de la transmissió de la pròpia llengua a favor de "la d'aquí".

És lícit pensar que la interpretació general és que la llengua "d'aquí", en singular, és el català, per la qual cosa en el cas d'aquest grup de professorat el factor de distorsió que implica plantejar un cas que afecta la pròpia llengua primera queda si més no apaivagat, cosa que explicaria una menor incoherència amb els resultats de l'afirmació que hem vist abans (taules 2 i 3 ).

Finalment, quant a aquesta qüestió de la substitució lingüística i la migració, encara hi havia una altra afirmació, aquesta vegada formulada com a principi, sense una aplicació concreta: "Lideal seria que 
cadascú pogués conservar la pròpia llengua, fins i tot quan marxa a viure lluny".

TAULA 6

GRAU D'ACORD AMB L'AFIRMACIO "L'IDEAL. SERIA QUE CADASCÚ POGUÉS CONSERVAR LA PROPIA LLENGUA, FINS 1 TOT QUAN MARXA A VIURE LLUNY"

\begin{tabular}{lrr}
\hline Grau d'acord & Freqüència & \multicolumn{2}{r}{ Percentarge } \\
\hline o: total desacord & $\mathrm{I}$ & $\mathrm{I}, 4$ \\
I: força en desacord & 2 & 2,7 \\
2: no gaire d'acord & $\mathrm{I}$ & $\mathrm{I}, 4$ \\
3: d'acord amb molts matisos & $\mathrm{IO}$ & 13,5 \\
4: d'acord en línies generals & $\mathrm{L}$ & $\mathrm{1}, \mathrm{s}, 9$ \\
5: totalment d'acord & 45 & 60,8 \\
Total vàlids & 73 & 98,6 \\
No contesten & $\mathrm{I}$ & $\mathrm{I}, 4$ \\
Total & 74 & 100,0 \\
\hline
\end{tabular}

Com es pot veure en la taula 6 , només 4 dels enquestats manifesten algun grau de desacord amb el principi general de transmissió de la pròpia llengua. Aquests resultats s'aproximen molt més als de la taula 2, que aplicava aquest principi als catalanoparlants desplaçats, que no pas a la taula 4 , que l'aplicava als desplaçats d'altres territoris lingüístics cap a Barcelona. Amb tot, l'acord aquí també és més tebi. Vegem si la Li hi té alguna incidència.

\section{TAULA 7}

PRINCIPI GENERAL DE CONSERVACIO DE LA PRÓPIA LLENGUA SEGONS LA LLENGUA PRIMERA DELS ENQUESTATS

L'ideal seria que cadascú pogués conservar la pròpia llengua, fins $i$ tot quan marxa a viure lluny.

Grau d'acord

\begin{tabular}{lccccccc}
\hline & 0 & 1 & 2 & 3 & 4 & 5 & Total \\
\hline LI & & & & & & & \\
Català & I & I & I & 6 & 9 & 25 & 43 \\
Tastellà & 0 & 1 & 0 & 4 & 5 & 20 & 30 \\
Totạl & I & 2 & I & 10 & 14 & 45 & 73 \\
\hline
\end{tabular}


Pel que fa al principi general, la incidència de la variable Lr és mínima. Tant el professorat de Li català com el de Li castellà es mostren d'acord amb la idea que conservar la pròpia llengua és positiu també per als migrants, i ho fa en proporcions força semblants. Les petites diferències indiquen que és el grup de Lr castellà qui hi mostra un acord més gran: només una enquesta se situa en l’àmbit del desacord.

\section{LA DIVERSITAT INTRALINGUISTICA}

急

El que Lippi-Green anomena ideologia de l'estàndard es manifesta tradicionalment d'una manera clara en l'estigmatització sistemàtica de tota forma lingüística que divergeixi d'un model de correcció predeterminat. La consideració de les varietats territorials d'una llengua com a formes inadequades és molt tradicional en el món de l'ensenyament espanyol.4 Tanmateix, ja fa anys que amplis sectors acadèmics enfoquen la varietat diatòpica sense una perspectiva jerarquitzadora i prescriptivista. Això ha arribat a l'escola obligatòria, com vam poder constatar a través de diferents entrevistes amb professorat de secundària (Comellas, "Representacions"). Alhora, però, nombrosos testimonis assenyalaven que en efecte la idea que certs trets lingüístics territorials eren inacceptables encara era present en la pràctica d'alguns professors. En aquest sentit, havíem inclòs a l'enquesta l'afirmació "L'alumnat d'origen llatinoamericà escriu i parla pitjor el castellà que el d'origen peninsular" per tal de sondejar sobre aquest aspecte, La majoria - dos de cada tres professors - s'hi va mostrar en desacord. Ara bé, que un terç del professorat hi mostri algun grau d'acord és sorprenent. A través de les entrevistes es va poder constatar que els factors que intervenen en aquest judici no són exclusivament lingüístics. Malgrat tot, pensem que si més no en part continua viu el prejudici tradicional que col-loca els conceptes de llengua i dialecte de manera dicotòmica i jerarquitzada, sobretot perquè observem que en aquest cas la diferència de resultats en funció de la llengua primera del professorat són mínimes, però en canvi és remarcable la diferència d'opinió entre el professorat dels diferents departaments lingüístics (català, castellà $i$ llengües estrangeres) i el de la resta d'àrees de coneixement, tal com es pot veure en la taula 8.

${ }^{4}$ En un estudi fer a centres d'ensenyament de Madrid, per exemple, s'afirma que "hemos registrado casos en los que los usos propios de las variedades del español utilizadas en América son calificados como erróneos" (Martín Rojo 195), o que "se recomiendan clases de 'castellanización' a personas que son hablantes nativos del español, como a los estudiantes de origen ecuatoriano, lo que se justifica señalando 'lo mal que hablan'" (Martín Rojo 224). 
TAULA 8

QUALITAT DEL CASTELLA DE L'ALUMNAT LLATINOAMERICA SEGONS EL DEPARTAMENT DELS ENQUESTATS

L'alumnat d'origen llatinoamericà escriu i parla pitjor el castellà que el d'origen peninsular.

Grau d'acord

\begin{tabular}{llllllll}
\hline 0 & $\mathrm{I}$ & 2 & 3 & 4 & 5 & Total \\
\hline
\end{tabular}

Departament

Llengües $\quad 12(33,3 \%) \quad 6(16,6 \%) \quad 9(25 \%) \quad 6(16,6 \%) \quad 2(5,5 \%) \quad$ I $(2,8 \%) \quad 36$ Altres $\quad 8(22,2 \%) \quad 6(16,6 \%) 7(19,4 \%) \quad 7(19,4 \%) 6(16,6 \%) \quad 2(5,5 \%) \quad 36$

\begin{tabular}{llllllll} 
Total & 20 & 12 & 16 & 13 & 8 & 3 & 72 \\
\hline
\end{tabular}

Gairebé un $42 \%$ del professorat no lingüístic es mostra d'acord amb un judici de valor de la qualitat de la llengua en funció de l'origen, mentre que entre el professorat de llengües la proporció baixa fins al $25 \%$. L'avaluació més negativa, doncs, prové d'àmbits de coneixement no directament relacionats amb la lingüística. Encara, però, val la pena subratllar dos aspectes més de la taula. D'una banda, la diferència entre els dos grups és sobretot important en el valor de desacord extrem i en el d'acord en termes generals. D'altra banda, en els valors més tebis, els dos del mig (no gaire d'acord i d'acord amb molts matisos) s'hi concentra prop del $40 \%$ tant d'un grup com de l'altre.

\section{L'ALUMNAT CADA VEGADA PARLA PITJOR}

La impressió que la llengua es degrada progressivament és molt freqüent i resistent. Es una manifestació més de la consideració del canvi com a degeneració. Ara bé, hi ha dues idees que susciten un gran consens en el món de la lingüística des de fa molt de temps: que el canvi lingüístic és inherent al llenguatge humà, i que no es pot demostrar que tingui una direcció objectivament qualificable (Aitchison), és a dir, que les llengües canvien, però ni milloren ni empitjoren, ni es fan més eficients ni més ineficients en termes globals (fenòmens com l'obsolescència en un procés de substitució no s'expliquen en termes de decadència linguística). Per què, doncs, tantes persones perceben aquest canvi com una degeneració? Segur que hi intervenen factors molt diversos, però en proposem com a mínim un: si acceptem la idea d'un model lingüuístic que prescriu allò que és correcte i condemna tota altra 
forma, per més que la produeixin parlants nadius competents, qualsevol canvi s'allunyarà necessàriament de la prescripció, que per definició tendeix a ser estàtica, fixada. Així doncs, el canvi continu s'allunya gradualment del model prescrit com a bo.

Ara bé, el que les enquestes van poder constatar és la vitalitat de la idea de decadència linguística entre el professorat. L'afirmació "Els alumnes cada vegada parlen pitjor" va obtenir un grau d'acord molt considerable. Només i2 dels 74 professors enquestats se situen a la banda del desacord, i encara la meitat només expressen el grau de desacord més suạu permès per l'enquesta. Vegem-ne els resultats complets en la taula 9 .

\section{TAULA 9}

GRAU D'ACORD AMB L'AFIRMACIÓ

"EL ALUMNES CADA VEGADA PARLEN PITJOR"

\begin{tabular}{lrr}
\hline Grau d'acord & Frequència & Percentatge \\
\hline o: total desacord & 3 & 4,1 \\
1: força en desacord & 3 & 4,1 \\
2: no gaire d'acord & 6 & 8,1 \\
3: d'acord amb molts matisos & 16 & 21,6 \\
4: d'acord en línies generals & 17 & 23,0 \\
5: totalment d'acord & 28 & 37,8 \\
Total vàlids & 73 & 98,6 \\
No contesten & 1 & 1,4 \\
Total & 74 & 100,0 \\
\hline
\end{tabular}

La freqüència més alta, 28 professors (gairebé un $38 \%$ ), és per a l'acord total sobre l'empitjorament progressiu de l'ús oral de la llengua per part de l'alumnat. Si hi sumem l'acord en termes generals, arribem a un $60 \%$, i la zona completa d'acord acapara el $80 \%$ de les respostes: no hi ha dubte que la idea de la degradació lingüística de l'alumnat és molt majoritària.

Una anàlisi mínimament acurada d'aquesta convicció del professorat necessita una mostra molt més gran i l'exploració de múltiples factors que són fora de l'abast d'aquest treball. Aquí únicament podem explorar alguna variable per provar d'orientar-nos. La distribució de respostes per departaments, per exemple, no ens dóna cap pista, com veiem a la taula ro. 


\section{TAULA Io}

EMPITJORAMENT PROGRESSIU DE LA LLENGUA DE L'ALUMNAT SEGONS EL DEPARTAMENT DELS ENQUESTATS

\begin{tabular}{lccccccc}
\hline \multicolumn{7}{c}{ Els alumnes cada vegada parlen pitjor } \\
\hline \multicolumn{7}{c}{ Grau d'acord } \\
\hline & 0 & 1 & 2 & 3 & 4 & 5 & Total \\
\hline $\begin{array}{l}\text { Departament } \\
\text { Llengües }\end{array}$ & 0 & 3 & 3 & 9 & 8 & 13 & 36 \\
Altres & 3 & 0 & 3 & 7 & 9 & 15 & 37 \\
Total & 3 & 3 & 6 & 16 & 17 & 28 & 73 \\
\hline
\end{tabular}

Si la hipòtesi de la distància progressiva entre model prescriptiu de llengua $i$ ús real subjecte al canvi està ben orientada, l'edat hauria de mostrar diferències d'opinió. Si més no, sembla que el professorat jove s'hauria de trobar més a prop dels usos linguístics innovadors de l'alumnat. La taula In, però, no ens ho indica així.

TAULA n

EMPITJORAMENT PROGRESSIU DE LA LLENGUA DE L'ALUMNAT SEGONS L'EDAT DELS ENQUESTATS

\begin{tabular}{lcccccc}
\hline \multicolumn{7}{c}{ Els alumnes cada vegada parlen pitjor. } \\
\hline \multicolumn{7}{c}{ Grau d'acord } \\
\hline Edat & 0 & I & 2 & 3 & 4 & 5 \\
fins a 30 & 0 & 0 & 0 & 0 & 3 & 1 \\
$31-35$ & I & I & 0 & I & 1 & 1 \\
$36-40$ & 0 & 0 & 1 & 1 & 2 & 3 \\
$41-45$ & 0 & 0 & 2 & 3 & 2 & 3 \\
$46-50$ & 2 & 1 & 2 & 6 & 4 & 10 \\
$51-55$ & 0 & 0 & 1 & 2 & 1 & 5 \\
$56-60$ & 0 & 1 & 0 & 2 & 4 & 4 \\
Total & 3 & 3 & 6 & 15 & 17 & 27 \\
\hline
\end{tabular}


De fet, dels 16 professors menors de 40 anys que van respondre l'enquesta, II mostren acord alt o absolut amb la idea de la degradació lingǘstica progressiva de l'alumnat. En el cas dels menors de 30 , la perspectiva de què gaudeixen és inevitablement molt curta, i tanmateix tots quatre se situen en l'acord alt o total. Dels només tres casos de desacord absolut que trobem en tota la mostra, dos se situen en una franja d'edat molt central, entre 46 i 50 anys, però aquesta és també la de més ocurrències. La petita dimensió de la mostra no permet generalitzar resultats. Sembla haver-hi una certa tendència a augmentar l'àrea d'acord ef augmentar l'edat, però el primer grup, els més joves, ho posaria en qüestió. D'altra banda, cal reconèixer que en aquesta franja només teníem quatre respostes. Si més no, ens permeten veure que la idea de la degradació lingüística no depèn de la pròpia experiència, de la pròpia constatació d'aquesta suposada degradació. És possible pensar que es tracta d'una idea que es transmet a priori?

\section{SABER LLENGUES I RENDIMENT ESCOLAR}

Tal com Dooly (aquest volum) mostra, sovint el professorat en actiu manifesta una representació de la diversitat lingüística a l'aula com a problemàtica. Ara bé, el multilingüisme en abstracte es considera, alhora, un valor, un avantatge. Una de les afirmacions que la nostra enquesta sol-licitava valorar era justament en aquest sentit: ${ }^{\circ} \mathrm{El}$ coneixement previ de llengües estrangeres suposa un avantatge per al rendiment dels alumnes". Els resultats obtinguts es representen a la taula I2.

\section{TAULA I2}

GRAU D'ACORD SOBRE SI EL CONEIXEMENT PREVI DE LLENGUUES ESTRANGERES SUPOSA UN AVANTATGE PER AL RENDIMENT DE L'ALUMNAT

\begin{tabular}{lrr}
\hline Grau d'acord & Freqüència & Percentatge \\
\hline I: força en desacord & $I$ & 1,4 \\
2: no gaire d'acord & 2 & 2,7 \\
3: d'acord amb molts matisos & 14 & 18,9 \\
4: d'acord en linies generals & 18 & 24,3 \\
5: totalment d'acord & 39 & 52,7 \\
Total & 74 & 100,0 \\
\hline
\end{tabular}


Com es pot veure, la banda d'acord és gairebé hegemònica. Només tres enquestes de les 74 hi mostren algun grau de desacord, i en canvi més del $50 \%$ consideren que en efecte és avantatjós conèixer llengües estrangeres. Ara bé, una altra afirmació de l'enquesta pretenia aproximar-se a aquesta qüestió des d'un altre angle, el de la competència linguística de l'alumnat immigrant, que molt sovint aporta aquesta diversitat lingüística que, en les entrevistes de Dooly, el professorat valora com a problemàtica i difícil. A la taula 13 podem veure la distribució del grau d'acord sobre l'afirmació "El principal problema escolar actual és la baixa competència lingüística de l'alumnat immigrant".

\section{TAULA 13}

GRAU D'ACORD SOBRE SI EL PRINCIPAL PROBLEMA ESCOLAR ACTUAL ÉS LA BAIXA COMPETENCIA LINGUUISTICA DE L'ALUMNAT IMMIGRANT

\begin{tabular}{lrr}
\hline Grau d'acord & Frequiència & Percentatge \\
\hline O: total desacord & 17 & 23,0 \\
1: força en desacord & 13 & 17,6 \\
2: no gaire d'acord & 13 & 17,6 \\
3: d'acord amb molts matisos & 18 & 24,3 \\
4: d'acord en línies generals & 9 & 12,2 \\
5: totalment d'acord & 3 & $4, \pi$ \\
Total vàlids & 73 & 98,6 \\
No contesten & 1 & 1,4 \\
Total & 74 & 100,0 \\
\hline
\end{tabular}

El mètode de l'enquesta tancada és, evidentment, deficitari en molts aspectes, $\mathrm{i}$ aquesta afirmació en posa de manifest algun. Com que l'única possibilitat de resposta és una escala de grau d'acord, no podem saber els innombrables matisos que poden inclinar l'opinió del professorat que respon. Per exemple, en l'ensenyament secundari el català en teoria és la llengua vehicular (encara que alguns estudis -com ara Riera et al., centrat a Granollers - ho posen en qüestió), i per tant la baixa competència en aquesta llengua pot suposar un entrebanc important en l'èxit escolar, també en alumnes que en canvi són parlants nadius de castellà (molts d'ells, immigrants). D'altra banda, el concepte de competència lingüística pot ser interpretat de manera molt diversa. Amb tot, pensem que la poca simetria dels resultats de l'anterior afirmació i aquesta tenen algun element de significació. Gairebé tot el professorat pensa que el coneixement de llengües estrange- 
res és positiu, però en canvi més del $40 \%$ mostra algun grau d'acord amb la idea que una baixa competència lingüística de l'alumnat immigrant pot arribar a constituir el principal problema actual de l'ensenyament. Aquesta divergència podria ser un indici de la doble consideració entorn del coneixement lingüístic: l'escola només valora un coneixement acadèmicament establert, que inclou unes determinades destreses en unes determinades llengües, però no pas qualsevol habilitat lingüística $i$ qualsevol varietat. Fins $i$ tot les destreses informals en una llengua com l'anglès, que com vèiem al començament és la Ilengua estrangefra més considerada i alhora matèria escolar omnipresent, poden ser molt poc valorades (Comellas, "Representacions" 194): no n'hi ha prou, malgrat els discursos sovint en aquest sentit, amb saber-se comunicar; cal mostrar domini de les destreses i les varietats acadèmicament sancionades. Així, coneixements de llengües de les quals ni tan sols sabem en general el nom difícilment seran valorats. Per la qual cosa podem pensar que, de fet, aquest avantatge del coneixement lingüístic es redueix bàsicament als registres acadèmics de català, castellà i anglès, i de manera més secundària d'altres llengües europees reconegudes.

\section{DISCUSSIÓ}

Les recerques recents de Dooly ("How Aware", Linguistic, aquest volum) mitjançant metodologia qualitativa mostren diferents aspectes de la consideració de la diversitat linguística per part del professorat. Dooly posa de manifest que, malgrat diferències de grau i de disposició a renegociar categories, tant professorat en actiu com en formació comparteixen representacions negatives de la diversitat lingüística, representacions lligades amb conceptes com ara "problematic", 'difficult', 'hard' and other such attributes. [...] Linguistic diversity, while seen as an advantage in some areas, was never constructed as a possible 'normal' situation, as can be observed in the way in which the teachers established the categories of 'normal' in opposition to 'other' classroom" (Dooly, Linguistic 256). Com Martín Rojo en diferents escoles de Madrid, també Dooly detecta "constructed categories of the language learner which included social and cultural traits as being relevant to the ability or inability to acquire a language" (Dooly, "How Aware" 108), categories que es poden constituir en profecies autoacomplertes.

La nostra recerca aporta dades complementàries entorn de les representacions lingüistiques del professorat. Així, hem vist que la diversitat lingüística, que d'una banda es considera problemàtica i s'articula com a anòmala, de fet és alhora considerablement invisible, un símptoma de la poca valoració real que es mereix. En un espai sociolingüís- 
tic com el català, es podria esperar una sensibilitat més esmolada cap a la preservació i la valoració de varietats lingüístiques vingudes d'altres zones del món que sovint es troben en situacions en què es podrien percebre paral-lelismes amb el català, especialment en el passat recent. Però en general veiem que la identificació de llengües va molt lligada a l'estatalitat i a l'oficialitat, i al mateix temps que la priorització de la llengua primera de l'alumnat no es té gaire en compte quan aquesta llengua no és la d'un mateix.

Pensem que el més interessant que ens ofereixen les opinions i els coneixements manifestats pel professorat és una certa incoherència. D'una banda, hi ha un petit desajustament entre una determinada opinió si l'apliquem a la llengua dels altres o a la pròpia. Vèiem que el professorat de primera llengua catalana valorava més positivament que els catalanoparlants conservin la pròpia llengua quan viuen fora de l'espai català que no pas que els immigrants conservin la seva aquí. És fàcil pensar que una certa percepció d'amenaça cap al català pugui impulsar a justificar que se li apliquin mesures excepcionals, que no creiem necessàries per a altres llengües. $\mathrm{O}$ senzillament potser només és una mostra de linguocentrisme.

D'altra banda, també es revela un grau d'incoherència entre els principis generals i les seves aplicacions particulars. Així, és difícil que algú manifesti opinions contràries a la igualtat general de les llengües o a la diferència de drets en funció de la llengua. Però l'acord en el principi general pateix una certa erosió quan se'n planteja una aplicació concreta: no és el mateix afirmar que és positiu que tothom conservi la pròpia llengua que afirmar que la immigració a Catalunya ha de continuar transmetent la llengua que porten a les següents generacions. La correcció política impulsa a fer afirmacions generals, però no és segur que s'interioritzin i s'estigui disposat a provar de projectar-les en la pròpia vida quotidiana.

És molt possible que un dels factors que contribueix a una major coherència sigui la reflexió i el coneixement explícit. Així, en un institut concret, l'IES Miquel Tarradell, la més alta valoraciô de la necessitat de conèixer la pròpia llengua coincidia amb un treball considerable d'informació sobre les realitats lingüístiques de l'alumnat. En el mateix sentit, el professorat de departaments lingüístics tendia menys a infravalorar el castellà de l'alumnat llatinoamericà, malgrat que, precisament pel fet que són els professors encarregats d'avaluar la llengua formal, semblaria que poden ser més sensibles a les divergències de l'estàndard. Alhora, però, la lingüística intenta desterrar la jerarquització de la variació que tradicionalment oposava conceptes com llengua i dialecte (malgrat que encara hi ha molta feina per fer, com ho demostren els llibres de text, Comellas, "Els llibres"). En aquest sentit, ha de ser fonamental la tasca feta per la formació de professionals de l'ensenyament. 
Dooly constata també en els seus treballs una diferència sensible en l'actitud del professorat en formació davant del professorat en actiu.

Una qüestió que l'enquesta desvela té precisament molta relació amb aquesta reflexió necessària entorn de les llengües: la convicció majoritària d'una degradació continuada de la llengua de l'alumnat. D'entrada, sembla una idea preconcebuda, molt difícilment objectivable i quantificable. Però la gran proporció d'acord en aquesta qüestió és sorprenent. Es tracta d'un prejudici tan potent que arriba fins $\mathrm{i}$ tot al professorat amb menys experiència i que, per tant, té molt pocs indicis`de primera mà? $O$ és fruit d'un conjunt de fets tan evident que es mostra gairebé immediatament i de manera poc contestable? Com és possible que totes les franges d'edat la percebin en un grau tan considerable, malgrat els canvis que l'escola ha experimentat els darrers quaranta anys? Sigui com sigui, es fa necessari aprofundir en la qüestió, sobretot perquè pel que sembla es podria tractar d'un cas fort de profecia autocomplerta, en el mateix sentit que ho pot ser l'expectativa diferenciada de rendiment escolar cap a grups d'alumnat lingüísticament i culturalment categoritzat.

\section{CONCLUSIÓ}

Aquests moments són sens dubte fonamentals pel que fa al tractament de les llengües a l'escola i a la societat. Barcelona (i altres espais) té a disposició un coneixement lingüístic aportat per milers de persones vingudes d'arreu del món que segurament no té parangó històric. Si s'aconsegueix que aquest saber es transmeti a les noves generacions, es mantindrà una societat amb habilitats lingüístiques amplíssimes en conjunt. Però si s'aplica una política d'assimilació agressiva amb la convicció que integrar-se vol dir deixar enrere tot el bagatge propi, aleshores es malbaratarà en poc temps. Molt d'aquest coneixement lingüístic és en mans d'uns infants que entren a les escoles amb representacions lingüístiques prèvies, generalment molt poc favorables a qualsevol valorització de les varietats lingüístiques no estatals, no oficials, no sancionades per la seva escola d'origen. Contribuir a canviarlos aquestes representacions, fer-los conscients que com a parlants d'altres llengües són dipositaris d'un saber excepcional i valuós sembla un camí apte per fomentar-los l'autoestima i, a través del reconeixement, incentivar-los l'empatia cap a la societat que els acull. Ara bé, això implica superar determinades representacions.

Si més no a l'àrea metropolitana de Barcelona cada substitució lingüística que es consuma i que habitualment es considera un èxit d'integració suposa un parlant més de castellà com a llengua primera. Potser e] model sociolingüístic tradicional de substitució o normalizzació té raó, i 
aleshores l'espai lingüístic català està abocat a una progressiva hegemonia del castellà. O potser és un bon model intralingüístic, però és possible una altra dinàmica interlingüística, $\mathrm{i}$ aleshores potser el català té la possibilitat de continuar usant-se en una realitat lingüística complexa. La voluntat d'homogeneització tradicional dels estats nació exclou la diversitat lingüística. Potser és possible renunciar a "somnis impossibles de societats compactes", com deia Emili Boix (Triar 212) i posar-se a construir un model de reconeixement mutu on hi hagi un lloc per a totes les llengües.

PERE COMELLAS UNIVERSITAT DE BARCELONA 


\section{ANNEX}

\section{QUESTIONARI}

Institut:

Departament o àrea:

Llengua primera:

Edat

Llengua o llengües que utilitzeu a classe:

A. Anoteu a continuació totes les llengües que sabeu amb seguretat que parla algun alumne de l'institut:

B. Anoteu per ordre d'importància les sis llengües que considereu que seria ideal que els vostres alumnes dominessin:

C. Citeu a continuació les llengües europees que no tenen cap mena d'oficialitat al seu país de què tingueu notícia:

D. Marqueu les possibilitars que creieu més adequades per facilitar la comunicació global d'escala mundial (si en marqueu més d'una, indiqueu amb un nombre l'ordre de preferència)

- L'extensió d'una llengua viva concreta - com ara l'anglès - com a llengua d'intercanvi mundial.

- La creació d'una llengua artificial que s'adoptaria a tot el món com a llengua segona.

- La potenciació del multilingüisme individual sense donar preferència $\mathrm{a}$ unes llengües concretes.

- La tria d'una llengua per a cada gran regió del món, de manera que amb sis o set llengües s'abastés tot.

- L'impuls (com a prioritat d'inversió en recerca) d'eines de traducció automàtica i del bilingüisme passiu.

- Una altra:

E. Qualifiqueu les afirmacions següents del o al 5 segons aquesta escala: o: total desacord; r: força en desacord; 2: no gaire d'acord; 3 : d'acord amb molts matisos; 4 : d'acord en línies generals; 5 : totalment d'acord. 


\section{E.r. Les llengües a Catalunya}

a) El català és una llengua amenaçada de desaparèixer en un futur proper.

b) És bo per als fills d'emigrants que els pares els parlin en la llengua d'aquí i no en la seva.

c) Per integrar-se a Catalunya és imprescindible aprendre català.

d) Com a mínim un institut de cada comarca hauria d'oferir una optativa de llengua aranesa.

e) L'única possibilitat que té el català de sobreviure és desplaçar el castellà.

f) El català només pot subsistir amb la independència política.

g) A una persona immigrant que parli català li serà més fàcil millorar la situació socioeconòmica.

h) El cost de mantenir l'oficialitat de dues llengües perjudica l'economia catalana.

i) Cal que tothom a Catalunya sigui com a mínim bilingüe castellà i català.

\section{E.2. Les llengües a Espanya}

a) Totes les oficines de l'administració pública, en tot el territori espanyol, haurien d'acceptar documentació en qualsevol de les llengües oficials de l'Estat.

b) És molt positiu que les comunitats catalanes instal-lades a altres zones d'Espanya mantinguin la llengua catalana a casa i la transmetin als fills.

c) L'Estat espanyol ha de tenir necessàriament una llengua general, no pot funcionar en un territori amb una llengua $i$ en un altre amb una altra.

d) Si les llengües oficials diferents del castellà aconseguissin ser hegemòniques en els seus territoris, seria impossible mantenir la unitat política d'Espanya.

e) A llarg termini el castellà serà l'ûnica llengua d'Espanya.

f) L'Estat espanyol fa poc per preservar i fer conèixer la diversitat lingüística d'Espanya.

g) 'Seria millor que els diners per normalització lingüística s'invertissinen despesa social. 
h) Fer més visibles i conegudes les diferents llengües d'Espanya a tot el territori contribuiria a cohesionar la societat espanyola.

i) No és possible ni desitjable que totes les persones que viuen al País Basc sàpiguen euskera.

\section{E.3. Les llengües al món}

a) Laş̧tendència natural del món actual porta a la desaparició de les llengües no oficials.

b) La gran varietat de llengües és un obstacle per al desenvolupament econòmic.

c) El més important és ser capaç de comunicar-se. Els elements formals (llengua, varietat dialectal o social, convencions d'escriptura, etc.) són secundaris.

d) D'aquí a un segle només quedaran al món un grapat de llengües com el xinès, el castellà o l'anglès.

e) Hi ha llengües més aptes que altres per a determinades àrees com la tecnologia o la filosofia.

f) El bilingüisme social sempre és transitori: quan dues llengües conviuen en el mateix territori, al final una de les dues s'imposa a l'altra.

g) La progressiva construcció d'un estat europeu farà imprescindible una llengua comuna.

h) Un estat hauria d'esforçar-se a preservar totes les llengües que es parlen al seu territori.

i) L’ideal seria que cadascú pogués conservar la pròpia llengua, fins i tot quan marxa a viure lluny.

i) En pocs anys la immensa majoria de la humanitat parlarà en anglès.

k) Totes les parles són iguals i haurien de gaudir de la mateixa acceptació i dels mateixos drets.

\section{E.4. Les llengües a l'escola}

a) El coneixement previ de llengües estrangeres suposa un avantatge per al rendiment dels alumnes.

b) La política lingüística actual de les comunitats autònomes amb llengua oficial pròpia posa en perill la competència lingüística en castellà de l'alumnat. 
c) El principal problema escolar actual és la baixa competència lingüística de l'alumnat immigrant.

d) Tots els instituts d'Espanya haurien d'oferir assignatures de totes les llengües oficials de l'Estat.

e) Els alumnes cada vegada parlen pitjor.

f) És molt important per a tothom avui dia parlar raonablement bé l'anglès.

g) L'alumnat d'origen llatinoamericà escriu i parla pitjor el castellà que el d'origen peninsular.

h) L'escola hauria d'ajudar els alumnes a mantenir viva la seva llengua materna.

i) La necessitat d'adquirir simultàniament diverses varietats lingüístiques interfereix negativament en el rendiment escolar de l'alumnat.

\section{REFERÈNCIES}

AITCHISON, Jean. Language Change: Progress or Decay? Cambridge: Cambridge UP, 1991.

Alegre, Miquel Ângel. Educació i immigració: l'acollida als centres educatius. Barcelona: Mediterrània, 2005.

Aracil, Lluís Vicent. Papers de sociolingüistica. Barcelona: La Magrana, 1982 .

-. Dir la realitat. Barcelona: Paisos Catalans, 1983.

Borx, Emili. Triar no és trair; identitat illengua en els joves de Barcelona. Barcelona: Ed. 62, 1993.

- "Les representacions: un camp de recerca des de l'antropologia lingǘstica per mantenir la diversitat". Congrés Linguapax: diversitat lingü̈stica, sostenibilitat i pau. Barcelona, Fòrum universal de les cultures, 2004. 10 març 2005 <http://www.linguapax.org/congreso4/indexcat.html>.

BorX, Emili, i Xavier VIL.A. Sociolingǘśtica de la llengua catalana. Barcelona: Ariel, 1998.

BOURDIEU, Pierre, Ce que parler veut dire: l'économie des échanges linguistiques. París: Fayard, 1982.

CALVET, Louis-Jean. Le marché aux langues: essai de politologie linguistique sur la mondialisation. París: Plon, 2002.

COMÉLLAS, Pere. "Representacions lingüístiques a l'ensenyament secundari obligatori públic de Barcelona." Tesi doct. U de Barcelona, 2005. 15 març 2007 <http://www.tdx.cat/>. 
-. "Els llibres de text i la ideologia de l'estàndard". VII Congrés de Lingüistica General: Barcelona, I8 a 21 d'abril de 2006. Barcelona: U de Barcelona, GELA, 2006. CD-ROM.

Dooly, Melinda. "How Aware are They?: Research into Teachers" Attitudes about Linguistic Diversity", Language Awareness 14. 23 (2005): 97-III.

-. Linguistic Diversity: "A Qualitative Analysis of Foreign Language Teachers' Category Assembly." Tesi doct. U Autònoma de Barcelona, 2005. 15 març 2007 <http://www.tdx.cat/ >.

Heller, Monica. "L'écologie et la sociologie du langage". L'écologie des langues: mélanges William Mackey = Ecology of Languages: Homage to William Mackey. Ed. A. Boudreau. París: L'Harmattan, 2002. 175-91.

JODELET, Denise, ed. Les représentations sociales. París: Presses Universitaires de France, 1989.

JUNYENT, M. Carme. Vida i mort de les llengües. Barcelona: Empúries, 1992.

- La diversitat lingǘstica: didàctica i recorregut de les llengües del món. Barcelona: Octaedro, 1999.

JUNYENT, M. Carme, et al. Les llengües a Catalunya: quantes llengües s'hi parlen?'Barcelona: Octaedro, 2005.

KREMNITZ, Georg. Multilingü̈isme social: aspectes institucionals, socials individuals. Barcelona: Ed. 62, 1993.

LiPPI-GREEN, Rosina. English wibt an Accent: Language, Ideology, and Discrimination in the United States. Londres: Routledge, 1997.

MARTIN ROJO, Luisa, dir. ¿Asimilar o integrar?: dilemas ante el multilingüismo en las aulas. Madrid: Ministerio de Educación, Cultura y Deporte, 2003.

Nussbaum, Luci, i Mercè Bernaus, eds. Didáctica de las lenguas extranjeras en la Educación Secundaria Obligatoria, Madrid: Síntesis, 2001.

Noguerol, Artur, i Luis GonZAlez, coords. Guias Praxis para el profesorado de ESO: Lengua y literatura: Contenidos, actividades $y$ recursos. Barcelona: CissPraxis, 2003.

POTTER, Jonathan. Representing Reality: Discourse, Rhetoric and Social Construction. Londres: Sage, 1996.

RIERA, Antoni, et al. Granollers: observatori sociolingüustic: cinc anys d'enquestes a 4t d'ESO. Granollers: Ajuntament de Granollers, 2006.

UNAMUNO, Virginia. Lengua, escuela y diversidad sociocultural: bacia una educación lingüüstica crítica. Barcelona; Graó, 2003.

VAN DIjא, Teun. Ideología y discurso: una intraducción multidisciplinaria. Barcelona: Ariel, 2003.

WOOLARD, Kathryn. Identitat i contacte de llengües a Barcelona. Barcelona: La Magrana, 1992. 